\title{
Gestáo municipal de resíduos e ambiente institucional no Rio Grande do Sul
}

Davide Carbonai. Universidade Federal do Rio Grande do Sul (Ufrgs), Porto Alegre, Brasil.

Juliana Baum. Tribunal de Contas do Estado do Rio Grande do Sul, Porto Alegre, Brasil.

Sergio Camiz. Universidade Federal do Rio Grande do Sul (Ufrgs), Porto Alegre, Brasil.

RESUmo | A Política Nacional de Resíduos Sólidos (PNRS) brasileira assigna aos municípios brasileiros a responsabilidade pela prestação dos serviços de limpeza urbana e a gestão de resíduos, no entanto, as pesquisas destacam as dificuldades, por parte dos próprios municípios, em adotar uma política que cumpra as obrigaçóes da lei antes mencionada. $\mathrm{O}$ presente artigo explora o problema de partir das correspondências entre o próprio ambiente institucional municipal (os principais fatores socioeconômicos, políticos e culturais) e a gestão municipal dos resíduos (especificamente, a presença de um Plano de Gestão Integrada de Resíduos Sólidos). Depois de uma breve introdução ao tema, o texto apresenta uma análise descritiva da difusão dos Planos nas microrregióes do Rio Grande do Sul, a continuação, o artigo apresenta uma análise de correspondências múltiplas que proporciona de forma exploratória um quadro geral da gestão municipal de resíduos em seu ambiente institucional.

PALAVRAS CHAVE | ambiente urbano, serviços urbanos, sustentabilidade urbana

abstract | The National Solid Waste Policy (Politica Nacional de Residuos Sólidos, PNRS) assigns Brazilian municipalities the responsibility of providing urban cleaning and waste management services; however, scholars report the difficulty of municipalities in adopting a policy that meets the obligations of the aforementioned law. This article explores the correspondences between the municipal institutional environment itself (the main socioeconomic, political and cultural factors) and municipal waste management (specifically, the presence of an Integrated Solid Waste Management Plan). After a brief introduction to the issue, this paper shows a descriptive analysis of the presence of these plans in the mesoregions of Rio Grande do Sul. The article then presents a multiple correspondence analysis that provides an exploratory overview of municipal waste management in its institutional environment.

KEYWORDS | urban environment, urban services, urban sustainability. 


\section{Introduçáo}

A partir do marco legal criado pela Política Nacional de Resíduos Sólidos (Lei 12305/2010) os municípios brasileiros tornam-se responsáveis em gerenciar os resíduos sólidos urbanos, desde a sua coleta até a sua disposição final. Para isso, a Política Nacional de Resíduos Sólidos (PNRS) estabelece um conjunto de instrumentos e dispositivos entre os quais a adoção compulsória de planos estaduais e municipais de gestão de resíduos, dentro de um prazo de dois anos após a data de sua publicaçáo. Assim, o principal intuito desta pesquisa é explorar a relação entre a adesão aos critérios da PNRS e um conjunto de fatores socioeconômicos ou sociopolíticos, referentes ao conceito de ambiente institucional.

O texto utiliza uma definição inclusiva do conceito de instituição (Ferrera, 1998, p. 10); logo, o tipo de cultura local, o desenvolvimento socioeconômico, a continuidade político-institucional, o tamanho do município - propriedades do conceito de ambiente institucional - representam fatores meritórios de análise: podem afetar a política local e a gestáo de resíduos sólidos urbanos (por exemplo, a presença dos principais instrumentos de planejamento na área ambiental). A pesquisa utiliza um conjunto de dados coletados pelo Tribunal de Contas do Estado do Rio Grande do Sul em 2016, e referentes aos 497 municípios do Estado (TCE-Rs, 2016). O referido banco de dados é utilizado conjuntamente com outras fontes estatísticas -Índice de Desenvolvimento Socioeconômico (IDESE), número de habitantes, subdivisão em macrorregióes, continuidade dos gestores, adesão a um consórcio- examinadas sob o ponto de vista descritivo e exploratório, por meio de associaçóes bivariadas e uma análise de correspondências múltiplas ( $\mathrm{ACM}$ ). Este desenho de pesquisa resulta também considerando a literatura -não muito rica- sobre o tema.

A análise de políticas públicas aborda a questão da gestão de resíduos sob diferentes perspectivas; de um lado as best practices de gestáo -por exemplo, as matrizes de indicadores como instrumento de avaliação e planejamento, como proposto por Santiago e Dias (2012) - do outro a pesquisa empírica, com finalidades explicativas e descritivas, tendo abordagens e foco de análise diferentes. A produção de resíduos depende de fatores de natureza diversa: morfológicos (Lamas, 2000), socioeconômicos (Silva, Barbieri, \& Monte-Mor, 2012), culturais como os hábitos de consumo (Mucelin \& Bellini, 2008) ou de confiança institucional, como no caso da confiabilidade da população nos serviços de limpeza urbana (Fonseca, 2006). Outros autores destacam que o modelo de gestão de resíduos depende das diferentes formas de participação e controle social em nível municipal (Reichert \& Mendes, 2014).

Conforme Rodrigues, Magalhães Filho e Pereira (2016), as despesas em resíduos nas capitais brasileiras dependem da forma de manejo escolhida por parte do município, inclusive no que tange à existência de um serviço de coleta seletiva: a privatização do serviço, por exemplo, tende a trazer pressóes que favorecem o aumento dos custos dos serviços oferecidos quando comparado com o mesmo serviço oferecido pelo poder público ou por parcerias público-privada. 


\section{A Política Nacional de Resíduos Sólidos}

Com a promulgação da Lei Federal 11445/2007, foram estabelecidas as diretrizes nacionais para o saneamento básico, abrangendo seus quatro componentes: abastecimento de água, esgotamento sanitário, manejo de resíduos sólidos e manejo de águas pluviais (Brasil, 2007). A Lei Federal 11445/2007, contudo, não apresentava dispositivos específicos direcionados à gestão integrada dos resíduos sólidos. A questão é em parte resolvida por meio da Lei Federal 12305/2010, que institui a Política Nacional de Resíduos Sólidos (PNRs). A PNRs dispôe sobre princípios, objetivos e instrumentos, bem como sobre as diretrizes relativas à gestáo integrada e ao gerenciamento de resíduos sólidos, às responsabilidades dos geradores e do poder público e aos instrumentos econômicos aplicáveis. Conforme a PNRS, a gestáo integrada dos resíduos sólidos gerados nos respectivos territórios, incumbe ao Distrito Federal e aos Municípios bem como prevê a existência de órgãos colegiados municipais que permitam a realização do controle social dos serviços de resíduos sólidos urbanos (Brasil, 2010). Não há qualquer atribuição para os Estados que seja voltada mais especificamente à gestão dos resíduos, comprovando que esta tarefa, de cunho operacional, cabe unicamente aos municípios, como explicitado no artigo 26 da Lei 12305/2010 (Brasil, 2010).

A gestão integrada de resíduos sólidos é definida no artigo 3, inciso XI, da PNRS, como o "conjunto de ações voltadas para a busca de soluçóes para os resíduos sólidos, de forma a considerar as dimensóes política, econômica, ambiental, cultural e social, com controle social e sob a premissa do desenvolvimento sustentável” (Brasil, 2010). O artigo 18 dessa mesma Lei estabelece também que a elaboração do Plano Municipal de Gestão Integrada de Resíduos Sólidos (PMGIRs) é condição para os municípios terem acesso aos recursos da Uniâo, a incentivos ou a financiamentos de entidades federais de crédito ou fomento para empreendimento e serviços relacionados à limpeza urbana e ao manejo de resíduos. A partir de então, a normativa vem, aos poucos, sendo implementada na forma de políticas públicas municipais, conforme os próprios instrumentos de planejamento municipal. No entanto, são constatadas várias dificuldades na sua implementação, tendo resultados geralmente incertos ou não satisfatórios (Brasil, 2010; Godoy, 2013; Jacobi \& Besen, 2011). ${ }^{1}$

Os Planos Municipais de Gestão Integradas de Resíduos Sólidos (PMGIRs) trazem inovaçóes relevantes: in primis, o escopo de planejamento que não deve tratar apenas dos resíduos sólidos urbanos (domiciliares e limpeza urbana), e sim de uma ampla variedade de resíduos sólidos (art. 13 da PNRs).

O conteúdo mínimo dos PMGIRs está previsto no art. 19, incisos I a XIX, da PNRs. Importante salientar que os Planos Municipais de Saneamento Básico (РМsв), disciplinados pela Lei 11445/2007, podem também contemplar o conteúdo mínimo

Dados atualizados sobre adoção dos instrumentos introduzido na PNRS podem ser encontrados no portal do Observatório da Política Nacional de Resíduos Sólidos em https://observatoriopnrs.org/ publicacoes/diagnostico-de-rsu/. 
estabelecido pela PNRS para o eixo de resíduos sólidos, de modo a otimizar a integração entre a Lei de Saneamento Básico e a PNRs, bem como para aumentar a escala de municípios que tenham um planejamento mais abrangente e orientado pelas diretrizes da Lei 12305/2010. Afinal, a PNRS integra a 11.445/2007 no sentido de possibilitar a adoçáo de instrumentos integrados de planejamento na área ambiental.

A PNRs estabelece também a possibilidade que o PMGIRs tenha conteúdo simplificado para municípios de pequeno porte (municípios com menos de 20.000 habitantes) com algumas ressalvas como no caso dos municípios integrantes de áreas de especial interesse turístico, entre outros. Desse modo, o Decreto no 7.404/2010, que regulamenta a PNRS, disciplina o conteúdo mínimo exigido para um Plano Municipal Simplificado de Gestão Integrada de Resíduos Sólidos (PSGIRs), em seu artigo $51, \$ 1^{\circ}$, incisos I a XIV.

No ano de 2010, o Instituto Brasileiro de Geografia e Estatística (IBGE), através da Pesquisa Nacional em Saneamento Básico, divulgou que 50,8\% dos resíduos gerados e coletados diariamente no Brasil não recebiam destinação apropriada, sendo depositados em vazadouros a céu aberto ou em aterros irregulares (IBGE, 2010). Esses dados foram posteriormente condensados por região e por Estado no Atlas de Saneamento, disponibilizado pelo IBGE em 2011: as Regióes Nordeste e Norte registraram as maiores proporçóes de municípios que depositam os resíduos sólidos em lixóes, apresentando as taxas de $89,3 \%$ e $85,5 \%$, respectivamente. Os estados da Região Sul foram os que registraram a menor taxa de destinação de resíduos em lixóes, com taxas de 2,7\% para Santa Catarina, 16,5\% no Rio Grande do Sul e 24,6\% no Paraná (ibge, 2011, p. 28).

Em pesquisa posterior, realizada em 2013 também pelo Instituto Brasileiro de Geografia e Estatística (IBGE), constatou-se que apenas 33,5\% dos municípios brasileiros possuíam Plano de Gestão Integrada de Resíduos Sólidos, nos termos estabelecidos na Política Nacional (IBge, 2014). Com relação às regiôes do país, no mesmo levantamento, destacou-se a Região Sul, onde 53,7\% dos municípios possuíam o Plano. Mais próximas da média nacional, situavam-se as Regióes Centro-Oeste $(35,3 \%)$ e Norte $(33,6 \%)$; sendo que a Região Sudeste $(28,8 \%)$ e a Nordeste $(23,9 \%)$ apresentaram os menores índices. Com relação aos Estados, foi verificado que os que possuíam maior percentual de municípios com Planos de Gestão Integrada foram Amazonas (80,6\%) e Paraná (63,4\%). Os Estados do Acre $(4,5 \%)$ e Piauí $(6,7 \%)$ registraram os menores percentuais de municípios que já haviam elaborado seus Planos. Dos 26 Estados, apenas quatro apresentaram Plano de Gestão Integrada de Resíduos Sólidos em mais da metade de seus municípios (IBGE, 2014).

\section{Delineamento da pesquisa}

O presente estudo explora um conjunto de dados coletados no ano de 2016 pelo Tribunal de Contas do Estado do Rio Grande do Sul (TCE-RS). O intuito do TCE-RS foi o de examinar o atendimento às diretrizes nacionais da PNRS, recolhendo informaçôes tanto sobre a elaboração e a adoção dos Planos Municipais de Saneamento Básico (PMSB) quanto da Gestão Integrada de Resíduos Sólidos (PMGIRs) nos 497 
municípios do Rio Grande do Sul (TCE-RS, 2016). A presente análise considera quatro variáveis coletadas na pesquisa do TCE-RS: (1) a presença de um PMGIRs; (2) a presença de um РмSв; 3) a presença de um serviço de coleta seletiva; 4) a presença no município de um Órgão colegiado (Conselho) para controle dos serviços municipais de gestão ambiental. Na tabela 1 são resumidamente apresentadas as nove variáveis (quatro tendo como fonte o TCE-RS e outras cinco com diferente fonte) utilizadas na análise descritiva e na análise exploratória (a tabela 5 inclui também uma distribuição de frequência das variáveis selecionadas).

O desenho da pesquisa leva em conta que a limpeza urbana e a gestão dos resíduos sólidos representam pilares essenciais do saneamento básico, conjuntamente com o abastecimento de água e o esgotamento sanitário e pluvial. Ainda que a legislação seja distinta (a Lei Federal 11445/2007 representa a principal ferramenta da Política Nacional de Saneamento Básico enquanto a PNRS surge com a Lei Federal 12305/2010), РмSB e PMGIRS representam instrumentos complementares e integrados do planejamento municipal, uma vez que o segundo é definido a partir dos critérios do primeiro. Por esse motivo, o banco de dados recolhe informaçóes sobre ambos os planos.

\begin{tabular}{|c|c|c|c|}
\hline $\begin{array}{l}\text { NOME DA } \\
\text { VARIÁVEL }\end{array}$ & DESCRIÇÃO & $\begin{array}{l}\text { TIPO DE } \\
\text { VARIÁVEL }\end{array}$ & FONTE \\
\hline PMGIRS & $\begin{array}{l}\text { Presença no município de um Plano Municipal de Ges- } \\
\text { tâo Integrada de Resíduos Sólidos (PMGIRs) }\end{array}$ & $\begin{array}{l}\text { Categórica } \\
\text { Duas categorias }\end{array}$ & $\begin{array}{l}\text { TCE-RS } \\
(2016)\end{array}$ \\
\hline PMSB & $\begin{array}{l}\text { Presença no município de um Plano Municipal de } \\
\text { Saneamento Básico (PMSB) }\end{array}$ & $\begin{array}{l}\text { Categórica } \\
\text { Duas categorias }\end{array}$ & $\begin{array}{l}\text { TCE-RS } \\
(2016)\end{array}$ \\
\hline Coleta seletiva & $\begin{array}{l}\text { Presença no município de um serviço de coleta seletiva } \\
\text { de resíduos sólidos }\end{array}$ & $\begin{array}{l}\text { Categórica } \\
\text { Duas categorias }\end{array}$ & $\begin{array}{l}\text { TCE-RS } \\
(2016)\end{array}$ \\
\hline $\begin{array}{l}\text { Órgão } \\
\text { colegiado }\end{array}$ & $\begin{array}{l}\text { Presença no município de um órgão colegiado (Con- } \\
\text { selho) para controle dos serviços municipais de gestão } \\
\text { ambiental }\end{array}$ & $\begin{array}{l}\text { Categórica } \\
\text { Duas categorias }\end{array}$ & $\begin{array}{l}\text { TCE-RS } \\
(2016)\end{array}$ \\
\hline $\begin{array}{l}\text { Continuidade } \\
\text { institucional }\end{array}$ & $\begin{array}{l}\text { Há continuidade partidária-institucional quando a } \\
\text { legenda partidária do Prefeito é recorrente pelo menos } \\
\text { duas vezes nas últimas três eleiçóes (eleiçóes de 2004, } \\
2008 \text { e 2012) }\end{array}$ & $\begin{array}{l}\text { Categórica } \\
\text { Duas categorias }\end{array}$ & $\begin{array}{l}\text { De Lara Ri- } \\
\text { bas (2014) }\end{array}$ \\
\hline Consórcio & Adesão do município a um Consórcio intermunicipal & $\begin{array}{l}\text { Categórica } \\
\text { Duas categorias }\end{array}$ & $\begin{array}{l}\text { SEMA } \\
(2015)\end{array}$ \\
\hline $\begin{array}{l}\text { Número de } \\
\text { habitantes }\end{array}$ & $\begin{array}{l}\text { Número de habitantes por município(cidade pequena se } \\
\text { inferior a } 100 \text { mil habitantes; médio-grande nos outros } \\
\text { casos) }\end{array}$ & $\begin{array}{l}\text { Categórica } \\
\text { Duas categorias }\end{array}$ & FEE (2016) \\
\hline IDESE & $\begin{array}{l}\text { Índice de Desenvolvimento Socioeconômico (IDESE) } \\
\text { recodificado em três categorias: Baixo (de } 56,76 \text { até } \\
66,98) \text {; Médio (de } 67 \text { até } 79,71) \text {; e Alto }(79,73 \text { até } 100 \text { ) }\end{array}$ & $\begin{array}{l}\text { Ordinal } \\
\text { Três categorias }\end{array}$ & FEE (2016) \\
\hline Macrorregióes & $\begin{array}{l}\text { Quatro macrorregiōes do Rio Grande do Sul (a partir } \\
\text { da divisão por conedEs do Rio Grande do Sul): Norte } \\
\text { Rio-Grandense; Centro Rio-Grandense; Metropolitana } \\
\text { de Porto Alegre; Sul Rio-Grandense }\end{array}$ & $\begin{array}{l}\text { Categórica } \\
\text { Quatro cate- } \\
\text { gorias }\end{array}$ & FEE (2016) \\
\hline
\end{tabular}

TABELA I | Descrição e tipos de variáveis utilizadas na análise descritiva FONTE: ELABORAÇÃO PRÓPRIA

A maioria das variáveis é analisada como categórica (com duas modalidades de resposta, geralmente no que se refere à existência ou não do item no município). 
Por exemplo, a variável 'Continuidade institucional' - recodificada em 'sim' ou 'não' - possui modalidade 'sim' quando um prefeito da mesma legenda partidária é eleito pelo menos duas vezes nas últimas três eleiçóes (eleiçóes de 2004, 2008 e 2012); a modalidade é 'não' no caso contrário (De Lara Ribas, 2015). As demais variáveis indicam: a adesão do município em um consórcio cuja principal atividade é a gestão de resíduos (geralmente os municípios são consorciados pela gestão de aterros); o número de habitantes (em duas categorias); o Índice de Desenvolvimento Socioeconômico IDESE (neste caso, recodificado em três categorias); e a subdivisão do Rio Grande do Sul em macrorregióes (quatro categorias) de acordo com a organização em Coredes do Rio Grande do Sul. As macrorregióes Sudoeste RioGrandense e Sudeste Rio-Grandense foram reclassificadas em uma única modalidade denominada de Sul Rio-Grandense.

São necessárias duas últimas notas metodológicas; em primeiro lugar, o estudo não tem como objeto a análise da efetividade dos planos: o que requer outras ferramentas de análise e informaçóes complementares mais detalhadas. Afinal, a pesquisa oferece um quadro geral para explorar a difusão dos planos, o que representa, de qualquer forma, um elemento útil na análise das políticas municipais de gestão ambiental. Em segundo lugar, o fato da análise de correspondências múltiplas ser apresentada, no texto, depois da análise por tabelas de contingência, serve uma mera questão de estilo. O raciocínio é mais circular: afinal, os testes de qui-quadrado apresentados na primeira parte, juntamente com a análise descritiva, (re)validam os resultados da análise de correspondências múltiplas apresentados em seguida.

\section{Gestão de resíduos sólidos e Planos de Saneamento Básico}

Resumidamente, o banco de dados de 2016 informa que 63,2\% dos municípios do Rio Grande do Sul dispóem de um pMgirs. Nesse contexto, a tabela 2 permite destacar que 285 municípios (58,3\% do total) apresentam concomitantemente um PMSB e um PMGIRS: a associação pode ser observada pelo resíduo padronizado acima de 2 . Afinal, 71,4\% dos municípios com Рмsв adotaram um plano de gestão de resíduos. No entanto, 114 municípios (23,3\%) dispóem somente de um Рмsв. Por outro lado, 24 municípios (4,9\%) adotaram somente o PMGIRs; enquanto (13,5\%) não dispóem de nenhum dos dois Planos. Ao todo, a não observância concomitante de ambos os planos (66 municípios) um total de 13,5\% dos municípios do Rio Grande do Sul.

Há uma associação significativa nas variáveis da tabela 2 (qui-quadrado igual a 63,25) e 3 (qui-quadrado igual a 12,43). A presença de um órgão colegiado de controle (Conselho) está significativamente associada com a presença de um PMGIRs: entre os municípios que possuem o órgão, a porcentagem que adota um PMGIRs é de $71,80 \%$, contra $56,30 \%$ dos municípios que não formalizaram um órgão colegiado de controle (tabela 3). 


\begin{tabular}{|c|c|c|c|c|}
\hline & & \multicolumn{2}{|c|}{ РMSB } & \multirow{2}{*}{ TOTAL } \\
\hline & & SIM & NÁO & \\
\hline \multirow{6}{*}{ PMGIRS } & & 285 & 24 & 309 \\
\hline & Sim & $71,4 \%$ & $26,7 \%$ & $63,2 \%$ \\
\hline & & $2,1^{* *}$ & $-4,4^{*}$ & \\
\hline & & 114 & 66 & 180 \\
\hline & Não & $28,6 \%$ & $73,3 \%$ & $36,8 \%$ \\
\hline & & $-2,7^{*}$ & $5,7^{* *}$ & \\
\hline \multirow{2}{*}{ Total } & & 399 & 90 & 489 \\
\hline & & $100 \%$ & $100 \%$ & $100 \%$ \\
\hline
\end{tabular}

TABELA 2 | PMGIRS e PMSB- tabela de contingência

** RESÍDUOS PADRONIZADOS> 2 (MARCADA ASSOCIAÇÃo POSITIVA); *RESÍDUOS PADRONIZADOS< -2 (MARCADA ASSOCiAÇÃo NEgATIVA).

FONTE: ELABORAÇÃO PRÓPRIA

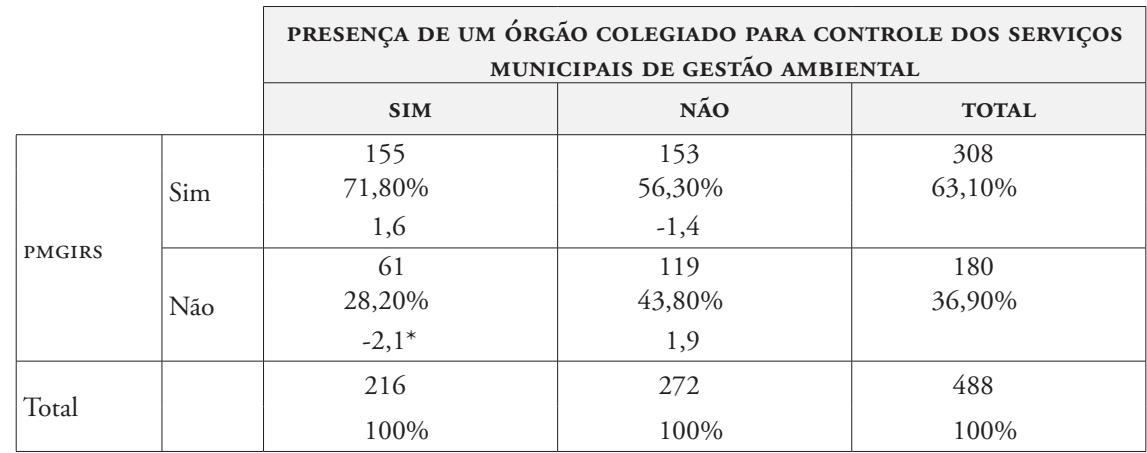

TABELA 3 | PMGIRs e órgáo colegiado - tabela de contingência

** RESÍDUOS PADRONIZADOS> 2 (MARCADA ASSOCIAÇÃo POSITIVA); *RESÍDUOS PADRONIZADOS< -2 (MARCADA ASSOCiaÇấO NEgATIVA).

FONTE: ELABORAÇÃO PRÓPRIA

Ao contrário das correlaçóes citadas anteriormente, o teste de qui-quadrado não resultou significativo no caso da associação entre a presença ou ausência de um PMGIRs e as seguintes variáveis: a adesão a um Consórcio intermunicipal (inclusão do município em um consórcio na área ambiental); o número de habitantes (duas categorias de municípios, acima ou abaixo de 100 mil habitantes); a continuidade institucional partidária. Resumindo, ainda que cerca da metade $(52,45 \%)$ dos municípios do Rio Grande do Sul façam parte de um Consórcio em matéria de gestão de resíduos sólidos (geralmente por causa da gestão de um aterro sanitário), isto pouco afeta na adoção de um PMGIRs: 51,1\% dos municípios com PMGIRS são consorciados, assim como 54,7\% dos municípios sem PMGIRs são consorciados. Em outras palavras, a associação entre a presença de consórcios com a existência de um PMGIRS não é significativa. 
Também não se demonstrou significativa a associação dos PMGIRS com o número de habitantes. Nas cidades pequenas (conforme o IBGE, é considerada pequena uma cidade abaixo de 100 mil habitantes, ou seja, 96,32\% dos municípios gaúchos) 63,1\% adotaram um PMGIRs, 61,1\% entra os municípios médios e grandes.

Também não é significativa a associação dos PMGIRs com a continuidade partidária institucional: $63,6 \%$ dos municípios com continuidade têm um plano, 60,3\% dos municípios sem continuidade de legenda têm um plano. No caso do indicador de desenvolvimento IDESE, ainda que a diferença entre os municípios com ou sem PMGIRS seja significativa, no caso de presença do Plano o valor do índice é igual a 0,74 , de pouco maior - pouquíssimo - do valor calculado nos municípios sem Plano $(0,72$; significância $\mathrm{p}<0,05) .^{2}$

\section{A política de resíduos nas macrorregióes do Rio Grande do Sul}

A pesquisa explora uma hipótese de difusão dos planos em relação ao contexto regional; como observado em outras pesquisas de tipo culturalista, em nível loco-regional, o tecido social pode afetar os resultados e a efetividade das políticas públicas (Bandeira, 2003; Monasterio, 2003). A adoção de uma variável relativa à subdivisão geográfica do Rio Grande do Sul enquadra-se sob o argumento da diferente dotação de capital social nas mesorregiốes do estado. Bandeira (2003), por exemplo, estabelece uma diferença territorial no Rio Grande do Sul semelhante ao que Putnam (2000) observou na Itália: haveria uma diferença entre o Norte colonial do estado, com predomínio do minifúndio e imigração italiana e alemá; e, em contraste, o Sul, com uma matriz ibérica, caracterizado pelo predomínio do latifúndio e o uso extensivo da mão-de-obra escrava.

A tabela 4 testa a associação entre as variáveis estudadas e a distribuição por macrorregióes; importante salientar: (1) o teste do qui-quadrado retorna valores significativos no que se refere à associação entre o nível regional e as variáveis PMGIRS, PMSB, Serviço de coleta seletiva; (2) os resíduos padronizados nas tabelas de contingências, sendo que um resíduo acima de 2 ou abaixo de -2 representa uma associaçáo significativa entre modalidades de duas variáveis categóricas - como no caso do cruzamento em correspondência da modalidade 'não' da variável PMGIRs e a modalidade Sul Rio-Grandense. Os dados apresentados demonstram que o planejamento em matéria ambiental está difundido, sobretudo, entre os municípios da Região Metropolitana de Porto Alegre (RMPA) e do Norte Rio-Grandense. Uma maneira direta de evidenciar esse destaque positivo da Regiáo Metropolitana de Porto Alegre (RMPA) e do Norte Rio-Grandense são os elevados percentuais de atendimento de todos os itens apresentados na tabela 4 , com valores próximos a $70 \% \mathrm{de}$ Presença de pMgIRs e de serviços de coleta seletiva de resíduos sólidos; assim como percentuais acima de $80 \%$ para a existência dos PMSB; em detrimento das regióes Centro e Sul Rio-Grandenses, que possuem percentuais de atendimento próximos a 50\% no que tange à presença de PMGIRs e ao serviço de coleta seletiva (aliás, em

Maiores detalhes sobre o IDESE podem ser encontrados no site da Fundação de Economia e Estatística. Em https://www.fee.rs.gov.br/indicadores/indice-de-desenvolvimento-socioeconomico/ 
torno de 30\% na adoção de um PMSB). Por fim, observa-se que, embora a difusão da política pública no Norte Rio-Grandense esteja acima da média, é na RMPA em que os Planos são mais adotados.

\begin{tabular}{|c|c|c|c|c|c|c|c|}
\hline & & & & & & \\
\hline & & & \multicolumn{4}{|c|}{ MACRORREGIÓES } & \multirow[b]{2}{*}{ TOTAL } \\
\hline & & & $\begin{array}{l}\text { NORTE RIO- } \\
\text { GRANDENSE }\end{array}$ & $\begin{array}{c}\text { CENTRO } \\
\text { RIO- } \\
\text { GRANDENSE }\end{array}$ & RMPA & $\begin{array}{c}\text { SUL RIO- } \\
\text { GRANDENSE }\end{array}$ & \\
\hline \multirow{4}{*}{ (a) PMGIRS } & Sim & $\begin{array}{l}\text { Std. } \\
\text { Residual }\end{array}$ & $\begin{array}{c}175 \\
65,54 \% \\
0,51 \\
\end{array}$ & \begin{tabular}{|l|}
43 \\
$50,59 \%$ \\
$-1,45$ \\
\end{tabular} & $\begin{array}{l}73 \\
77,66 \% \\
1,78\end{array}$ & $\begin{array}{l}18 \\
40,91 \% \\
-1,85 \\
\end{array}$ & $\begin{array}{l}309 \\
63,06 \%\end{array}$ \\
\hline & \multirow{2}{*}{ Não } & \multirow{2}{*}{$\begin{array}{l}\text { Std. } \\
\text { Residual }\end{array}$} & $\begin{array}{l}92 \\
34,46 \%\end{array}$ & $\begin{array}{l}42 \\
49,41 \%\end{array}$ & $\begin{array}{l}21 \\
22,34 \%\end{array}$ & $\begin{array}{l}26 \\
59,09 \%\end{array}$ & $\begin{array}{l}181 \\
36,94 \%\end{array}$ \\
\hline & & & $-0,67$ & 1,89 & $-2,33^{*}$ & $2,42^{* *}$ & \\
\hline & \multicolumn{2}{|c|}{ Total } & $\begin{array}{l}267 \\
100 \% \\
\end{array}$ & $\begin{array}{c}85 \\
100 \% \\
\end{array}$ & $\begin{array}{c}94 \\
100 \% \\
\end{array}$ & $\begin{array}{c}44 \\
100 \% \\
\end{array}$ & $\begin{array}{l}490 \\
100 \%\end{array}$ \\
\hline \multirow{3}{*}{$\begin{array}{l}\text { (b) Coleta } \\
\text { seletiva de } \\
\text { resíduos } \\
\text { sólidos }\end{array}$} & Sim & $\begin{array}{l}\text { Std. } \\
\text { Residual }\end{array}$ & $\begin{array}{l}189 \\
70,79 \% \\
1,02 \\
\end{array}$ & $\begin{array}{l}47 \\
55,29 \% \\
-1,19 \\
\end{array}$ & $\begin{array}{l}64 \\
68,09 \% \\
0,28 \\
\end{array}$ & $\begin{array}{l}22 \\
50,00 \% \\
-1,29 \\
\end{array}$ & $\begin{array}{l}322 \\
65,71 \%\end{array}$ \\
\hline & Náo & $\begin{array}{l}\text { Std. } \\
\text { Residual }\end{array}$ & $\begin{array}{l}78 \\
29,21 \% \\
-1,42 \\
\end{array}$ & $\begin{array}{l}38 \\
44,71 \% \\
1,64 \\
\end{array}$ & $\begin{array}{l}30 \\
31,91 \% \\
-0,39 \\
\end{array}$ & $\begin{array}{l}22 \\
50,00 \% \\
1,78 \\
\end{array}$ & $\begin{array}{l}168 \\
34,29 \%\end{array}$ \\
\hline & \multicolumn{2}{|c|}{ Total } & $\begin{array}{l}267 \\
100 \%\end{array}$ & $\begin{array}{c}85 \\
100 \%\end{array}$ & $\begin{array}{c}94 \\
100 \%\end{array}$ & $\begin{array}{c}44 \\
100 \%\end{array}$ & $\begin{array}{l}490 \\
100 \%\end{array}$ \\
\hline \multirow{3}{*}{$\begin{array}{l}\text { (c) Plano } \\
\text { Municipal } \\
\text { de Sanea- } \\
\text { mento } \\
\text { Básico }\end{array}$} & Sim & $\begin{array}{l}\text { Std. } \\
\text { Residual }\end{array}$ & $\begin{array}{c}223 \\
83,52 \% \\
0,35 \\
\end{array}$ & $\begin{array}{l}63 \\
75,00 \% \\
-0,67 \\
\end{array}$ & $\begin{array}{l}83 \\
88,30 \% \\
0,72 \\
\end{array}$ & $\begin{array}{l}30 \\
68,18 \% \\
-0,98 \\
\end{array}$ & $\begin{array}{l}399 \\
81,60 \%\end{array}$ \\
\hline & Náo & $\begin{array}{l}\text { Std. } \\
\text { Residual }\end{array}$ & $\begin{array}{l}44 \\
16,48 \% \\
-0,73 \\
\end{array}$ & $\begin{array}{l}21 \\
25,00 \% \\
1,41\end{array}$ & $\begin{array}{l}11 \\
11,70 \% \\
-1,51 \\
\end{array}$ & $\begin{array}{l}14 \\
31,82 \% \\
2,07^{* *} \\
\end{array}$ & $\begin{array}{l}90 \\
18,40 \%\end{array}$ \\
\hline & \multicolumn{2}{|c|}{ Total } & $\begin{array}{l}267 \\
100 \% \\
\end{array}$ & $\begin{array}{c}84 \\
100 \% \\
\end{array}$ & $\begin{array}{c}94 \\
100 \% \\
\end{array}$ & $\begin{array}{c}44 \\
100 \% \\
\end{array}$ & $\begin{array}{l}489 \\
100 \%\end{array}$ \\
\hline
\end{tabular}

tabela 4 | Macrorregióes do Rio Grande do Sul e Planos municipais - tabela de contingência

QUI-QUADRADO SIGNIFICATIVO (P<O,OOI): A. 24,25; B. I 2,20; C. I I I $8 .{ }^{*}$ RESÍDUOS PADRONIZADOS> 2 (MARCADA ASSOCIAÇÃO POSITIVA); * RESÍDUOS PADRONIZADOS< - 2 (MARCADA ASSOCIAÇÃO NEGATIVA). FONTE: ELABORAÇĀO PRÓPRIA

\section{Análise de correspondências múltiplas}

A análise das tabelas de contingência em relação aos Planos retorna um quadro onde a presença do planejamento na área de resíduos, ainda que com diferenças significativas entre macrorregióes, não está associada ao tamanho populacional ou à continuidade institucional, observando-se apenas uma leve mas significativa associaçáo com o IDESE. A Análise de Correspondências Múltiplas (ACM) permite explorar a interação global deste conjunto de variáveis e apontar eventuais variáveis que podem funcionar como intervenientes nas associaçóes bivariadas anteriores, e, portanto, potencialmente afetar o resultado da análise bi-variada (Gifi, 1990; 
Carvalho, 2017). Mais especificadamente, foram utilizadas as técnicas desenvolvidas pelo grupo de Data Theory System (DTSs) da Universidade de Leida, na Holanda, cujas aplicaçóes podem ser encontradas em softwares de notável popularidade como o spss.

\begin{tabular}{|c|c|c|c|c|c|c|c|}
\hline \multirow{2}{*}{ VARIÁVEL } & \multirow{2}{*}{ DESCRIÇÃO } & \multirow{2}{*}{$\begin{array}{l}\text { MODALI- } \\
\text { DADES }\end{array}$} & \multirow{2}{*}{$\mathbf{N}$} & \multicolumn{2}{|c|}{ COORDENADAS } & \multicolumn{2}{|c|}{ PESOS } \\
\hline & & & & $\mathbf{I}$ & 2 & $\mathbf{I}$ & 2 \\
\hline \multicolumn{8}{|l|}{ Ativas } \\
\hline \multirow{2}{*}{ PMGIRS } & \multirow{2}{*}{$\begin{array}{l}\text { Plano municipal de Gestão } \\
\text { dos Resíduos }\end{array}$} & Sim & 309 & 0,51 & $-0,16$ & 0,44 & 0,04 \\
\hline & & Não & 181 &,- 87 & ,29 & & \\
\hline \multirow{2}{*}{ Seletiva } & \multirow{2}{*}{$\begin{array}{l}\text { Presença de serviço munici- } \\
\text { pal de coleta seletiva }\end{array}$} & Sim & 322 & 0,35 & 0,24 & 0,23 & 0,11 \\
\hline & & Não & 168 & $-0,66$ & $-0,45$ & & \\
\hline \multirow{2}{*}{ PMSB } & \multirow{2}{*}{$\begin{array}{l}\text { Plano Municipal de } \\
\text { Saneamento básico }\end{array}$} & Sim & 399 & 0,34 & $-0,10$ & 0,50 & 0,04 \\
\hline & & Não & 90 & $-1,58$ & ,47 & & \\
\hline \multirow{2}{*}{ Conselho } & \multirow{2}{*}{$\begin{array}{l}\text { Órgão colegiado para } \\
\text { controle dos serviços de } \\
\text { saneamento básico }\end{array}$} & Sim & 216 & 0,64 & $-0,25$ & 0,32 & 0,05 \\
\hline & & Não & 272 & $-0,50$ & 0,21 & & \\
\hline \multirow{3}{*}{ IDESE } & \multirow{3}{*}{ IDESE em três categorias } & Baixo & 79 & $-0,81$ & $-0,59$ & 0,19 & 0,37 \\
\hline & & Médio & 339 & 0,006 & $-0,19$ & & \\
\hline & & Alto & 79 & 0,74 & 1,35 & & \\
\hline \multirow{2}{*}{ Consórcio } & & Sim & 238 & $-0,05$ & $-0,81$ & 0,00 & 0,59 \\
\hline & & Não & 259 & 0,04 & 0,72 & & \\
\hline \multicolumn{8}{|l|}{ Ilustrativas } \\
\hline & \multirow{2}{*}{ Continuidade partidária } & Sim & 418 & 0,01 & $-0,03$ & & \\
\hline & & Não & 79 & $-0,11$ & 0,08 & & \\
\hline & \multirow{4}{*}{ Macrorregiōes } & Norte & 270 & 0,11 & 0,26 & & \\
\hline & & Centro & 85 & $-0,21$ & $-0,17$ & & \\
\hline & & RMPA & 98 & 0,13 & $-0,63$ & & \\
\hline & & Sul & 44 & $-0,63$ & $-0,01$ & & \\
\hline & \multirow[b]{2}{*}{ População residente } & Pequena & 478 & $-0,01$ & $-0,02$ & & \\
\hline & & $\begin{array}{l}\text { Média- } \\
\text { Grande }\end{array}$ & 18 & 0,22 & 0,30 & & \\
\hline
\end{tabular}

TABELA 5 | Elenco das variáveis ativas e ilustrativas na Análise de

Correspondências Múltiplas

FONTE: ELABORAÇÁO PRÓPRIA

Na tabela 5 são apresentadas as variáveis ativas e ilustrativas incluídas na ACM (já exibidas na tabela 1). Para a realização da análise, entre as variáveis com modalidades ativas (que participam na definição dos dois fatores extratos) foram elencadas: (1) a presença ou a ausência do PMGIRs no município; (2) a existência ou não de serviço de coleta seletiva no município; (3) a elaboração ou não do PMSB por parte do município; (4) a institucionalização ou não de um órgão colegiado (Conselho) para fins de controle externo dos serviços de saneamento básico; (5) o IDESE, reclassificado em três categorias - Baixo de 56,76 até 66,98; Médio de 67 até 79,71; e Alto de 79,73 até 100; (6) a adesão ou não a um Consórcio intermunicipal na área de gestão de resíduos. O módulo presente em spss assume que todas as variáveis ativas sejam utilizadas em nível de variáveis categóricas simples. No que tange 
às chamadas variáveis ilustrativas (que não participam da definição dos fatores) foram eleitas: (1) a continuidade institucional-partidária; (2) as macrorregióes do Rio Grande do Sul, reclassificadas em quatro modalidades: Norte Rio-Grandense, Centro Rio-Grandense, Região Metropolitana de Porto Alegre, Sul Rio-Grandense; (3) o número de habitantes por município, reclassificado conforme os critérios do IBGE, em cidades 'pequenas' ou 'médio-grandes'. O programa alcança a convergência depois de 41 iteraçóes: a quadragésima segunda iteração não melhora de forma significativa o resultado da quadragésima primeira iteração. A inércia total é igual a 0,48-0,28 explicado pelo primeiro fator (dimensão 1), 0,20 pelo segundo fator (dimensão 2).

A tabela 5 ilustra também as assim chamadas medidas de discriminação das variáveis ativas por cada fator - essa medida de discriminação é igual ao quadrado dos respectivos pesos sobre as dimensôes. Um alto valor de discriminação de uma variável sobre uma dimensão (fator) indica que as modalidades daquela variável são muito discriminadas naquela dimensão. Analisando os coeficientes é possível interpretar os fatores, ou seja, denominar cada fator na base das modalidades que apresentam valores discriminantes maiores na dimensão. Enquanto no fator 1 pesam sobretudo as variáveis de planejamento (o PMGIRs, o PMSB, o Conselho), no caso do fator 2 pesa sobretudo a variável Consórcio e IDESE.

A figura resultante da ACM pode ser interpretada a partir de algumas consideraçôes gerais: quando duas modalidades apresentam coordenadas distantes do centro e posicionam-se próximas no espaço fatorial, as duas modalidades tendem a ser diretamente associadas (concordantes: a frequência empírica é maior que a teórica na hipótese de independência); por outro lado, quando duas modalidades apresentam coordenadas distantes do centro mas posicionam-se uma no lado negativo e outra no lado positivo do fator, no sentido de terem sinais opostos, as duas modalidades tendem a serem associadas inversamente (discordantes: a frequência conjunta empírica é menor que a teórica na hipótese de independência). Na figura 1, é possível visualizar a proximidade (associação) das modalidades 'sim', uma vez que todas estâo posicionadas no lado positivo do fator 1; e, ao lado oposto das modalidades 'não', que aparecem na parte negativa do fator. A única exceção dessa tendência é relativa à variável correspondente aos Consórcios (discriminada sobretudo pelo fator 2, pouco pelo primeiro fator).

Assim como observado na nota anterior referente à análise bivariada, observa-se também na figura 1 que a continuidade partidária e o número de habitantes por município resultam independentes das outras modalidades, já que ambas resultaram concentradas no centro da figura. Também a presença ou ausência de um Consórcio é pouco discriminada na dimensão 1 , uma vez que seus resultados positivos e negativos ficam posicionados próximos ao eixo vertical (onde pesam sobretudo as variáveis IDESE e Consórcio). Por fim, verifica-se que a figura divide as modalidades em dois grupos (ao longo, sobretudo, da dimensão 1):

- O eixo negativo da dimensão 1 que agrupa praticamente todas as modalidades 'não' (ou seja, municípios que não possuem PMGIRs, PMSB, Conselho, 
Continuidade partidária, Serviço de coleta seletiva), também abrange a região Sul e Centro Rio-Grandense, além do IDESE baixo;

- Por outro lado, o eixo positivo que agrupa as modalidades 'sim' (ou seja, municípios que possuem PMGIRs, PMsB, Conselho, Continuidade partidária, Serviço de coleta seletiva), abarca também as categorias de IDESE alto e médio, além de contemplar as regióes Norte Rio-Grandense e a RMPA.

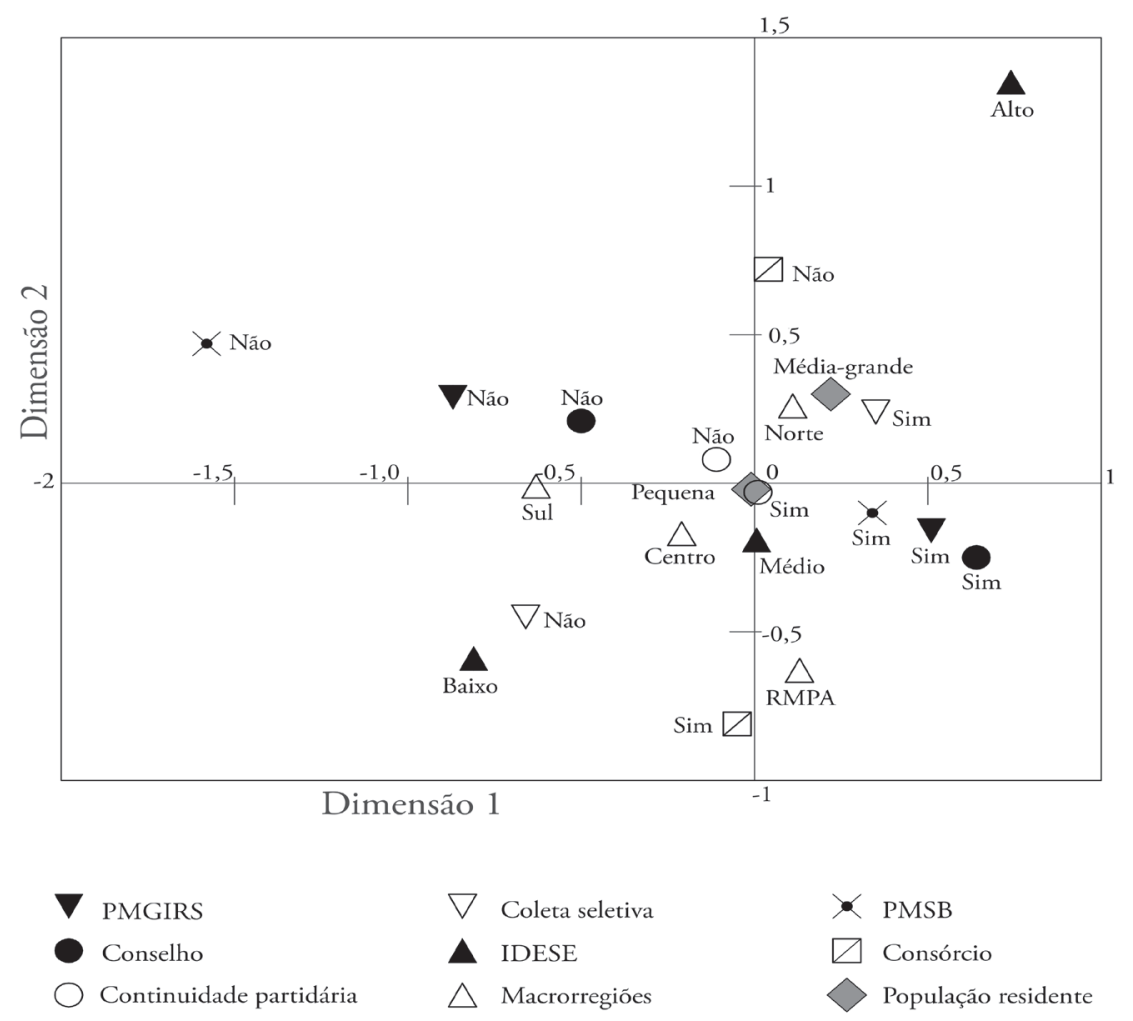

FIgura I | Análise de Correspondências Múltiplas ACM (modalidades e fatores) FONTE: ELABORAÇÃO PRÓPRIA

\section{Conclusóes}

A distribuição dos itens na figura 1 é (re)validada pelas associaçôes apresentadas ao longo do texto. A análise bi-variada destaca a associação existente entre a adoção de um PMgIrs e a presença de outros instrumentos de políticas públicas na área da gestão ambiental, tais como o serviço de coleta seletiva, a presença de um PMsB. O que sugere que as best practices na gestão de resíduos dependem de políticas e práticas de gestão reiteradas do governo local: quando o município se ativa na adoção de um plano, a prática favorece a adoção de outros serviços ou instrumentos de planejamento na área ambiental. Os resultados remetem ao modelo incremental 
de tomada de decisão conforme proposto por Lindblom (1959): onde problemas e soluçôes são definidos, redefinidos e revisados e em vários momentos do ciclo de políticas públicas e da tomada de decisão, e as decisóes são consideradas dependentes das decisóes tomadas no passado.

A fiscalização societária é associada à presença dos instrumentos de planejamento na gestão ambiental: de um lado, na análise por ACM, as regióes gaúchas com maior dotação de capital social se posicionam mais próximas dos eixos positivos na figura (associando-se à presença de planos), enquanto a regiáo Sul posiciona-se próxima dos eixos negativos, do outro, a presença ou ausência de planos está associada aos itens referentes à presença de um órgão de controle social em nível municipal.

Ao contrário, fatores teoricamente relevantes como a continuidade partidária-institucional, a adesão a um consórcio e o número de habitantes por município, não apresentam significativa associação à difusão dos instrumentos de planejamento. Afinal, como em Reichert e Mendes (2014, p. 302), a adoção dos instrumentos de planejamento na área ambiental depende do desenvolvimento em nível municipal de um modelo ou sistema próprio de gestáo pública, incorporado nas práticas de administração municipal, e fiscalizado societariamente ou por meio do controle social dos conselhos.

\section{Referências bibliográficas}

Bandeira, P. S. (2003). Algumas hipóteses sobre as causas das diferenças regionais quanto ao capital social no Rio Grande do Sul. Em S. M. S. Correa (ed.), Capital social e desenvolvimento regional (pp. 15-59). Santa Cruz do Sul: Ed. Edunisc.

Brasil. Presidência da República (2007). Lei 11445, de 5 de janeiro de 2007. Brasília, DF. http://www.planalto.gov.br/ccivil_03/_ato2007-2010/2007/lei/111445.htm. Brasil. Presidência da República (2010). Lei 12305, de 2 de agosto de 2010. Brasília, DF. http://www.planalto.gov.br/ccivil_03/_ato2007-2010/2010/lei/112305.htm.

Carvalho, H. (2017). Análise Multivariada de Dados Qualitativos - Utilização da ACM com o SPSS. Lisboa: Ediçóes Sílabo.

Ferrera, M. (1988). Le trappole del welfare. Bolonha: Il Mulino.

Fundação de Economia e Estatística Siegfried Emanuel Heuser /FEE). (2016). FEedados. http://feedados.fee.tche.br/feedados/.

Gifi, A. (1990). Nonlinear Multivariate Analysis. New York: Wiley \& Sons.

Godoy, M. R. B. (2013). Dificuldades para aplicar a Lei da Política Nacional de Resíduos Sólidos no Brasil. Caderno de Geografia, 23(39), 1-12. http://periodicos.pucminas.br/ index.php/geografia/article/view/4784?baimopppphlnohdb

Instituto Brasileiro de Geografia e Estatística (IBGE) (2011). Atlas de saneamento 2011. Rio de Janeiro: 2011. http://biblioteca. ibge.gov.br/biblioteca-catalogo?view=detalhes\& $\mathrm{id}=253096$.

Instituto Brasileiro de Geografia e Estatística (IвGE) (2008). Pesquisa Nacional de Saneamento Básico - PNSB 2008. Rio de Janeiro. http://www.ibge.gov.br/home/estatistica/ populacao/condicaodevida/pnsb2008/default.shtm. 
Instituto Brasileiro de Geografia e Estatística (IBGE) (2014). Pesquisa de Informaçôes Básicas Municipais: Perfil dos Municípios Brasileiros 2013. Rio de Janeiro. https://www. academia.edu/7045777/munic2013.pdf.

Jacobi, P. R. \& Besen, G. R. (2011). Gestão de resíduos sólidos em São Paulo: Desafios da sustentabilidade. Estudos Avançados, 25(71), 135-158. https://dx.doi.org/10.1590/ S0103-40142011000100010136

Lamas, J. M. R. G. (2000). Morfologia urbana e desenho da cidade. Lisboa: Fundação Calouste Gulbenkian.

Lindblom, C. E. (1959). The science of "muddling through". Public Administration Review, 19(2), 79-88. https://faculty.washington.edu/mccurdy/SciencePolicy/Lindblom \%20 Muddling\%20Through.pdf.

Monasterio, L. M. (2003). Medindo o Capital Social: uma análise das regiôes do Rio Grande do Sul. In S. M. S. Souza, Capital Social e Desenvolvimento Regional (pp. 61-84). Santa Cruz do Sul: Editora Edunisc.

Mucelin, C. A. \& Bellini, M. (2008). Lixo e impactos ambientais perceptíveis no ecossistema urbano. Sociedade \& Natureza, 20 (1), 111-124. http://www.scielo.br/pdf/sn/v20n1/ a08v20n1.

Putnam, R. (2000). Comunidade e Democracia. A experiência da Itália Moderna. Rio de Janeiro: Editora FGV.

Reichert, G. A. \& Mendes, C. A. B. (2014). Avaliação do ciclo de vida e apoio à decisão em gerenciamento integrado e sustentável de resíduos sólidos urbanos. Engenharia Sanitária e Ambiental, 19(3), 301-313. http://www.scielo.br/pdf/esa/v19n3/14134152-esa-19-03-00301.pdf.

Ribas, V. L. (2014). Partidos Politicos em eleiçôes municipais no Rio Grande do Sul (1996-2012). 2014. Trabalho de Conclusão de Curso (Graduação em Ciências Sociais - Ciência Política). São Borja: Universidade Federal do Pampa.

Ribas, V. L. (2015). O Desempenho do Partido Progressista em Eleiçóes Municipais no Rio Grande do Sul (1996-2012). Revista Eletrônica de Ciência Política, 6(2), 91-108. http://dx.doi.org/10.5380/recp.v6i2.42642

Rodrigues, W., Magalhaes Filho, L. N. L., \& Pereira, R. S. (2016). Análise dos Determinantes dos custos de resíduos sólidos urbanos nas capitais estaduais brasileiras. Urbe. Revista Brasileira de Gestão Urbana, 8(1), 130-141. http://dx.doi.org/10.1590/2175-3369. 008.001.AO02

Santiago, L. S. \& Dias, S. M. F. (2012). Matriz de indicadores de sustentabilidade para a gestão de resíduos sólidos urbanos. Engenharia Sanitária e Ambiental, 17(2), 203-212. http:// dx.doi.org/10.1590/S1413-41522012000200010

Secretaria do Meio Ambiente do Estado do Rio Grande do Sul (sEma) (2015). Plano Estadual de Resíduos Sólidos (PERS-RS). Versão final. http://www.pers.rs.gov.br/noticias/ noticia-08042015.html.

Silva, H., Barbieri A. F., \& Monte-Mor, R. L. (2012). Demografia do consumo urbano: um estudo sobre a geração de resíduos sólidos domiciliares no município de Belo Horizonte. Revista Brasileira de Estudos de População, 29(2), 421-449. http://dx.doi. org/10.1590/S0102-30982012000200012 
Tribunal de Contas do Estado do Rio Grande do Sul (TCE-RS) (2016). Pesquisa Planos Municipais de Saneamento Básico e de Gestão Integrada de Residuos Sólidos. https://portal.tce.rs.gov. $\mathrm{br} /$ portal/page/portal/tcers/consultas/pmsr 